NASA Technical Memorandum 102074

\title{
Space Station Freedom Electrical Power System Hardware Commonality With the United States Polar Platform
}

Lorra L. Rieker and Francis M. Haraburda

Lewis Research Center

Cleveland, Ohio

Prepared for the

24th Intersociety Energy Conversion Engineering Conference cosponsored by the IEEE, AIAA, ANS, ASME, SAE, ACS, and AIChE Washington, D.C., August 6-11, 1989

\section{N/SA}




\section{SPACE STATION FREEDOM ELECTRICAL POWER SYSTEM HAROWARE COMMONALITY}

\section{WITH THE UNITED STATES POLAR PLATFORM}

Lorra L. Rieker and Francis M. Haraburda

National Aeronautics and Space Administration

Lewis Research Center

Cleveland, Ohio 44135

\section{ABSTRACT}

The National Aeronautics and Space Administration has adopted the policy to achieve the maximum practical level of commonality for the space Station Freedom program in order to significantly reduce life cycle costs. Commonality means using identical or similar hardware/software for meeting common sets of functionally similar requirements. Presented in this paper is information on how the concept of commonality is being implemented with respect to electric power system hardware for the Space Station Freedom and the U.S. Polar Platform. Included is a historical account of the candidate common items which have the potential to serve the same power system functions on both Freedom and the Polar Platform.

\section{PROGRAM DESCRIPTION AND OBJECTIVES}

Two of the Space Station Freedom program objectives are to establish a permanently manned research facility in low-Earth orbit and to provide an unmanned platform for long duration scientific and operational observations in near-polar orbit.

In order to bring this about, the test and development responsibilities for the program elements that form these facilities are distributed among four NASA centers - Marshall Space Flight Center (MSFC), Johnson Space Center (JSC), Goddard Space Flight Center (GSFC), and Lewis Research Center (NASA Lewis). This allows the program to draw upon unique skills and resources throughout the agency. Overall program direction and system engineering and integration (SE\&I) activity is to be provided by the Program office (Level II) in Reston, VA (Fig. 1).

In this scheme, Work Package 03 (WP-03), NASA GSFC and its prime contractor General Electric, has the responsibility for the definition, development, utilization, and servicing of platforms. Initially there were two platforms in Phase I of the program, a polar platform and a coorbiting platform. The latter, planned to occupy a low-Earth orbit the same as the space station, has been shifted downstream to Phase II of the space station program. While still considered in the design and development process, the coorbiting platform will not be discussed further here. The Polar Platform will support missions to make terrestrial, biological and geological observations, oceanographic and ice activity studies. It will also be used for Earth lower- and upper-atmospheric monitoring and research, solar observations, and plasma physics measurements ( $\mathrm{Fig} .2$ ).

Work Package 04 (WP-04), NASA Lewis and its prime contractor Rocketdyne, has responsibility for definition and development of the space station solar power modules and distributed electric power system hardware and software. These both are part of the manned base configuration. The latter also comprises a part of the Polar Platform. The manned base has as its mission to serve as a laboratory, observatory, servicing facility, transportation node, assembly facility, manufacturing facility. storage depot, and staging base ( $F i g .3$ ).

While the mission goals and characteristics of each of these structures in space will be different, each will require development of many of the same type systems. This gives rise to the notion of using "common" hardware in order to perform similar functions in a variety of applications. This approach has been adopted by the program. A commonality program was initiated to reduce space station operating costs and crew time required for training, operations, and maintenance. The program aims at reducing costs by: (1) using existing designed hardware from other programs, (2) using identical or similar designs to satisfy similar functional requirements, (3) reducing the types of spares required, (4) using qualified standard parts, and (5) using common sof tware, hardware, and interfaces.

The electric power system hardware candidates that could potentially perform the functions of power generation and storage, and power management and distribution on the Space Station Freedom and the Polar Platform are shown in Table I.

To discuss how the commonality process has influenced the selection of this power system hardware, a historical account from the WP-04 perspective is given below.

\section{PROGRAM DEFINITION AND PRELIMINARY DESIGN (PHASE B)}

A comprehensive program definition phase was completed in January 1987, which provided a review of space station systems and a more thorough understanding of the overall space station architecture. WP-04 participated in trade studies that focused on 
comparing the electric power system technology candidates and determining the best common option for the station and piatforms.

Specific Design Drivers

Some unique characteristics of the Polar Platform must be considered in the hardware designs for use in this application. The first of these is that the platform will be unmanned and have a low visitation frequency. Therefore, a long design life, less harsh operating ranges, and high reliability are features stressed for use on the platform. Another characteristic is a requirement for solar array retractability. This is a necessity during servicing and reorientation maneuvers in order to reduce drag. In addition, the platform designs must respond to power requirements of few. relatively predictable users. In contrast, the space station will be manned, making servicing events possible, and will provide utility-type power to many users upon demand. Both the platform and station will incorporate a capability for growth.

\section{Photovoltaic Power Generation}

The power generation source baselined in Phase $B$ for the station and platform was a planar silicon flexible panel array utilizing 8- by $8-\mathrm{cm}$ solar cells. It included a dual blanket, deployment/retraction capability, and protected Kapton substrate. Operational voltage would be a nominal $160 \mathrm{~V} d c$. A summary of other options traded against the selected features are shown in Table II.

Several key factors formed the bas is and rationale for the selected design. It was the minimum cost, minimum mass choice. The dual blanket design offered an aspect ratio for the platform solar array that would minimize interference with the payloads' field of view. The design could easily accommodate the lower platform power generation requirements by using panel and blanket box designs identical to the station but using fewer panels and adjusting the blanket box preload. This design is also compatible with the need for retractability. The concept was favored as well from the standpoint that it had been previously demonstrated with the OAST-1 flight experiment. A schematic of the solar array assemblies is shown in Fig. 4.

Growth is accomplished by either launching the growth configuration initially or by replacing the entire array assembly on-orbit. This design is expected to have a 15 year serviceable lifetime with the design point for the station at 4 years and for the platform at 10 years.

\section{Energy Storage}

The energy storage device baselined in Phase $B$ for the station and platform was an individual pressure vessel nickel-hydrogen battery. The rationale for this decision was that this choice was a low mass option, with low waste heat dissipation requirements, and high reliability. The other options under consideration were nickel-cadmium batteries, energy wheels, and alkaline regenerative fuel cells. Energy whee is were considered to be at too early of a stage of development and were dropped early as a viable option (Fig. 5). Nickelcadmium batteries would impose an extreme mass penalty for both the station and platform. Alkaine regenerative fuel cells (RFC) were the most competitive option but presented several drawbacks. The first of these was that the volume was too large for both applications but especially for the Polar platform where it is desirable to package the energy storage device and other platform subsystem equipment in standard ORU boxes. Second, the need to dissipate high heat loads generated by the RFC requires a significantly larger radiator surface. While this imposes a mass penalty on the station, the platform utilizes a passive thermal control system by radiating off the side surfaces of the standard ORU boxes. The large size and increased mass make this approach infeasible. Finally, it is unknown if the RFC could meet a 100 percent power requirement after a single failure on the platform without incorporating an extreme amount of redundancy and increasing mass, making its reliability questionable. As a result, a nickel-hydrogen battery (Fig. 6) was selected as the baseline. It would be comprised of 3.5 in. diameter cells of the pineapple-slice design. However, the capacity remained an issue with WP-O4 baselining a 65 AH cell and WP-O3 baselining a $40 \mathrm{AH}$ cell. The difference hinged primarily upon thermal control considerations. Nickel-hydrogen cells have flown in spacecraft but in geosynchronous orbit with a different cycle regime than the low-Earth orbit cycle in the space station program. The five year design life needed for the batteries aboard the space station and platform is considered achievable al though not yet proven. Growth would be accomplished by replication of battery assemblies to meet increasing power requirements.

\section{Power Management and Distribution}

The functions of power management and distribution on the Polar Platform parallel those of the space Station Freedom. The functions begin with the acceptance of $160 \mathrm{~V} \mathrm{dc}$ and inverting it to $208 \mathrm{~V} \mathrm{ac}, 20 \mathrm{kHz}$, single-phase power. This is accomplished using a series resonant switching topology in the inverter units. Power output and voltage output ratings differ between the station and platform inverter units as expected. Each of the station inverters is rated $25 \mathrm{kVA}$ with an output voltage of $440 \mathrm{Vac}$. Each of the platform inverters is rated 5 kVA with an output voltage of $208 \mathrm{Vac}$. The initial number of inverter units on the platform is four, which meet program requirements for normal and peak power and system fault tolerance.

The second function of the EPS system is to provide system and load fault protection. This function is provided by ac remote power controllers (RPC). The RPC's are solid-state switching devices which include programmable trip settings and programmable time to trip settings. The devices provide voltage, current, and status data to the power management controlier for the purpose of monitoring the EPS system's health and optimizing the usage of 
power. The current ratings of the RPC's provided for station and platform use will cover loads of $10 \mathrm{~W}$ to $15 \mathrm{~kW}$.

Additional common hardware for station and platform use are $a c / d c$ and $d c / d c$ converters of $100 \mathrm{~W}$ output ratings. These converters will provide $28 \mathrm{~V} d c, \pm 15 \mathrm{~V} d c$ and $\pm 5 V \mathrm{dc}$ outputs for control voltage required by the hardware and system control processors.

\section{DESIGN AND DEVELOPMENT (PHASE C/D)}

Phase $\mathrm{C} / 0$ of the space station program is in progress. Work is proceeding with an interactive process between the work package centers and Level II of refining design requirements and honing in on designs. The power generation and energy storage technology selections identified in Phase $B$ continue to be the options of choice for the photovoltaic system. But the program has introduced a number of key changes to the program baselines that require significant changes to the design baselines of common platform and station hardware. The first of these has been a change in the secondary distribution system on the station and platform from a $20 \mathrm{kHz}$ architecture to a $120 \mathrm{~V}$ dc architecture. In light of this, a change in the baseline design of the solar array to produce a $120 \mathrm{~V}$ dc array for primary distribution on the Polar Platform rather than a $160 \mathrm{~V}$ dc array is being investigated. This could effectively change the level of solar array identicality from the panel to the production module level. Other impacts include the elimination of the dc/ac inverters and the ac/dc converters and the replacement of the ac RPC's with dC RPC's. A second key program change was the baselining of an expendable launch vehicle (ELV) to launch the Polar Platform. This means that the common hardware must be designed for compatibility with the environment imposed by this vehicle as well as that of the space shuttie.

In order to converge on a design in areas where a discrepancy exists, WP-03 and WP-04 continue to exchange technical information. WP-03 and WP-04 met specifically to discuss thermal considerations for the batteries on the platform and these discussions resulted in a decision to baseline a 81 AH battery assembly for use on the station and platforms. Solar array sizing factors were discussed, leading to another alteration that shifted the solar array design point from 10 to 5 years. other areas addressed during technical interchange meetings have been the use of a common gimbal design for solar array pointing on the station and platform. This item, by mutual agreement was different enough in form and function and had many different constraints driving the designs for the platform and station applications, to consider making this item unique and produced by WP-03. The process followed to bring this about is described in Fig. 7. A final decision has not yet been reached. Through the technical interchange meetings and discussions the following list of current WP-04 to WP-03 deliverables shown in Table III has been generated.

\section{WHAT'S NEXT}

There is still a great deal of coordination yet to be done between the electric power system provider, WP-04, and the platform program element provider, WP-03. This is needed to resolve discrepancies in the intersite deliverables lists, which indicate the hardware deliverables between NASA centers. Items for delivery at the development and flight fidelity, quantities of each deliverable, and delivery dates must still be negotiated in many cases. A set of definitive requirements must be completed and installed in the appropriate documents to flow down into the design specifications. The test and verification plans of each the work packages must be discussed and complementary approaches developed for the hardware that is to be transferred between work packages. This includes further definition of support equipment. Interaction will also occur during the preliminary design review (PDR) and critical design review (CDR) processes. WP-03 will participate in the WP-04 review of the contractor's overall design approach for selected flight and ground systems hardware configurations that will also be used on the Polar Platform. The PDR will assure compatibility with the program and affected work package requirements and the producability of the design approach. The results of this review will constitute an update to the configuration baseline and approval of the approach so that the contractor may proceed with detailed design. When the detailed design is essentially complete, a CDR will be held, also with participation by WP-O3, to determine compliance of the completed design with the technical requirements of the NASA baseline. The results of this review will constitute another update to the configuration baseline. Approval of the approach identifies the production baselines.

\section{KEY CHALLENGES}

The key challenge of this project in terms of commonality comes from the size and scope of the program. The number of end items being produced, the number of centers and contractors involved in producing them, the diversity of the missions they will be used for, the different launch vehicles that will place them in orbit, and all the functional and physical interfaces to control make this a very difficult task to manage. In general it is a very dynamic program requiring quick reactions to programmatic changes and fast-paced planning. Once changes are in place, however, the trail of programmatic interfaces, the documentation chain, and contractual structure that must be updated to incorporate these is so intricate that the actua? implementation in many cases occurs much later.

\section{CONCLUSION}

The Space Station Freedom and Polar Platform will be some of the most complex space facilities ever built. WP-03 and -04 have been jointly involved in defining the power system for these applications by determining the practical level of common hardware. This is cooperatively being done 
with the goal of reducing the program cost of design, development, testing, assembly and checkout, and operation of these facilities. The configuration of the hardware that has been determined to be common is currently being refined. Production of Polar Platform and Space Station Freedom hardware is scheduled to begin in 1992.

\section{ACKNOWLEDGMENTS}

The authors wish to acknowledge and thank our counterparts in the WP-04 Space Station SE\&I Division, and the WP-03 Space Station Project OfficePlatform Segment for their contributions in supporting the effort to define common electric power system hardware for the Polar Platform.

\section{REFERENCES}

1. Space Station Development Plan. Submitted by NASA to the Committee on Science, Space and Technology, U.S. House of Representatives, Nov. 1987.

TABLE 1. - POWER SYSTEM COMMONALITY CANDIDATES

[The Electric power system hardware for the platform will be provided by WP-04 unless a program decision is made to make the $i$ tem unique. In that case, the item would be designed and developed by WP-03.]

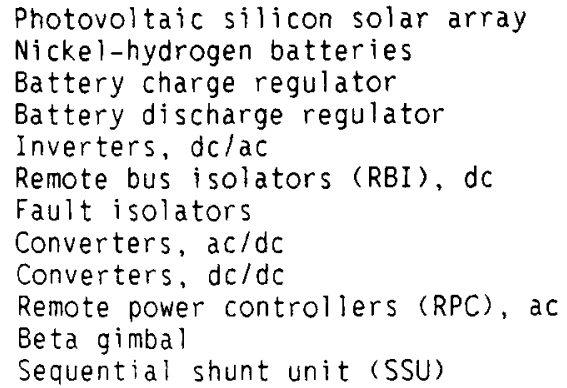

2. Photovoltaic System Recommendations: Configuration Selections for Station and Platform EPS. NASA LERC Space Station Systems Presentation. Jan. 1986.

3. Energy Storage Trade Study. TRW Space and Technology Group, Nov. 1985.

4. Work Package 4 Configuration Management Plan NASA LeRC-SS-0012, Mar. 15, 1989

5. Work Package 03 System Concept Review Presentation Package. GE Astro Space, Mar. 15, 1989.

6. Space Station Commonality Process Requirements. SSP 30285, Rev. A, June 30, 1988.

TABLE II. - SOLAR ARRAY TRADE STUDY OPTIONS

(a) Cell characteristics

\begin{tabular}{|c|c|}
\hline Selected feature & Other trade study options \\
\hline Planar & Concentrator \\
\hline Silicon & Gallium arsenide \\
\hline $\begin{array}{l}\text { Infrared trans- } \\
\text { parent BSFa }\end{array}$ & $\begin{array}{l}\text { Infrared reflective BSF/BSRa, } \\
\text { Conventional BSF/BSR } \\
\text { BSRb }\end{array}$ \\
\hline $\begin{array}{l}6-\mathrm{mil} \text { cover } \\
\text { glass }\end{array}$ & $\begin{array}{l}2-m i] \text { cover glass } \\
4-m i l \text { cover glass } \\
8-m i l \text { cover glass }\end{array}$ \\
\hline $\begin{array}{l}\text { Ceria cover } \\
\text { glass }\end{array}$ & $\begin{array}{l}\text { Fused-silica cover glass } \\
\text { Microsheet }\end{array}$ \\
\hline $8-m i l$ cell & $\begin{array}{l}6-m i 1 \text { cell } \\
10-m i 1 \text { cell } \\
12-m i 1 \text { cell }\end{array}$ \\
\hline 8 by $8 \mathrm{~cm}$ & $\begin{array}{l}2 \text { by } 4 \mathrm{~cm} \\
3 \text { by } 6 \mathrm{~cm} \\
6 \text { by } 6 \mathrm{~cm}\end{array}$ \\
\hline
\end{tabular}

(b) Array characteristics

\begin{tabular}{|c|c|}
\hline Selected feature & Other trade study options \\
\hline $\begin{array}{l}\text { Deployable/ } \\
\text { retractable }\end{array}$ & Deployable/Erectable \\
\hline Flexible blanket & Rigid panel \\
\hline Protected Kapton & $\begin{array}{l}\text { Kapton-F } \\
\text { PTFE (Teflon) and } \mathrm{SiO}_{2} \\
\text { Others }\end{array}$ \\
\hline $\begin{array}{l}\text { Dual blanket } \\
\text { array wing }\end{array}$ & Single blanket array wing \\
\hline Nominal $160 \mathrm{~V} d c$ & $\begin{array}{l}200 V d c \\
400 V d c \\
>400 V d c\end{array}$ \\
\hline
\end{tabular}

aback-side field

back-side reflective. 
TABLE III. - WP-04 TO WP-03 DELIVERABLES

[In addition to these items a solar array handling set and transport container will be shared by WP-03 and WP-04 if scheduling permits.]

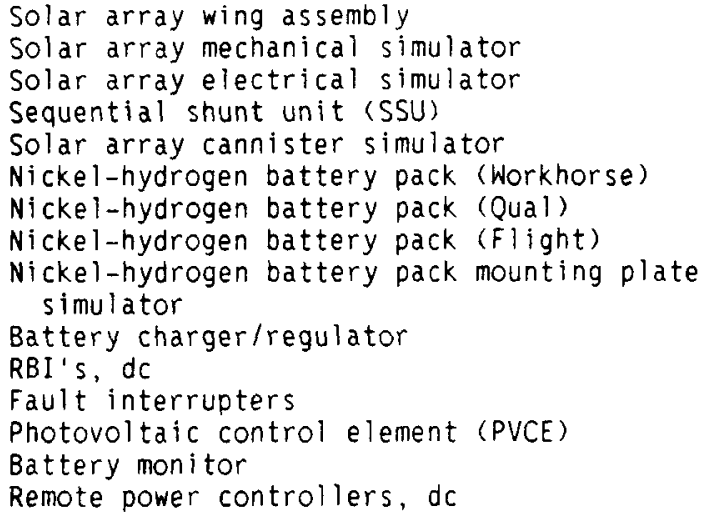

LEVEL 1

LEVEL II
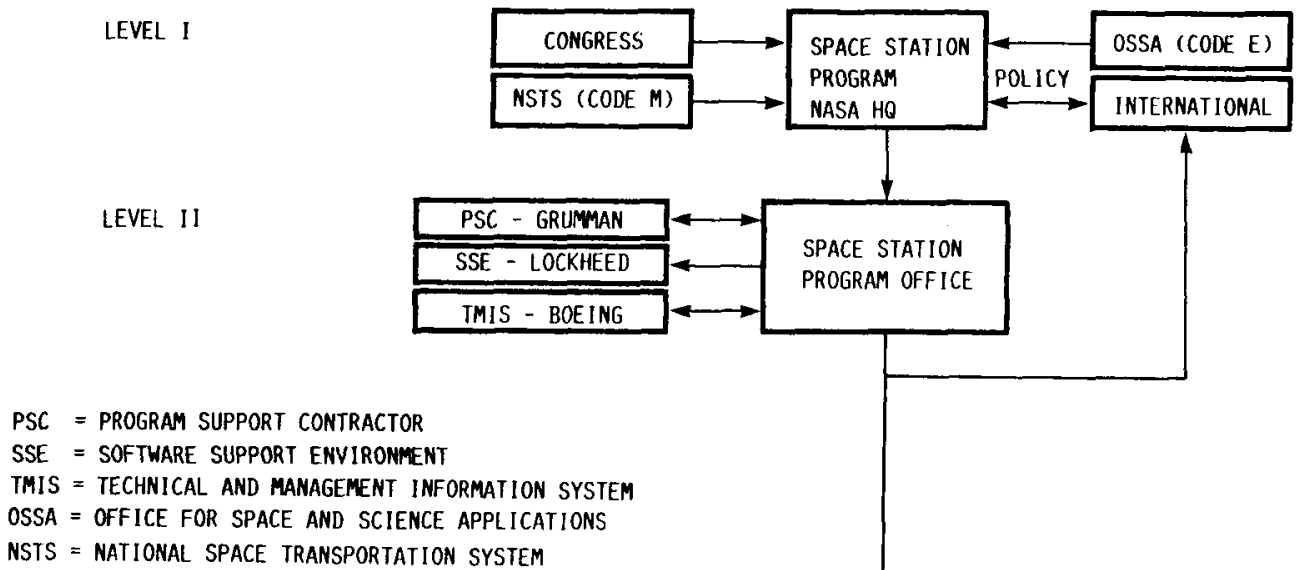

LEVEL III

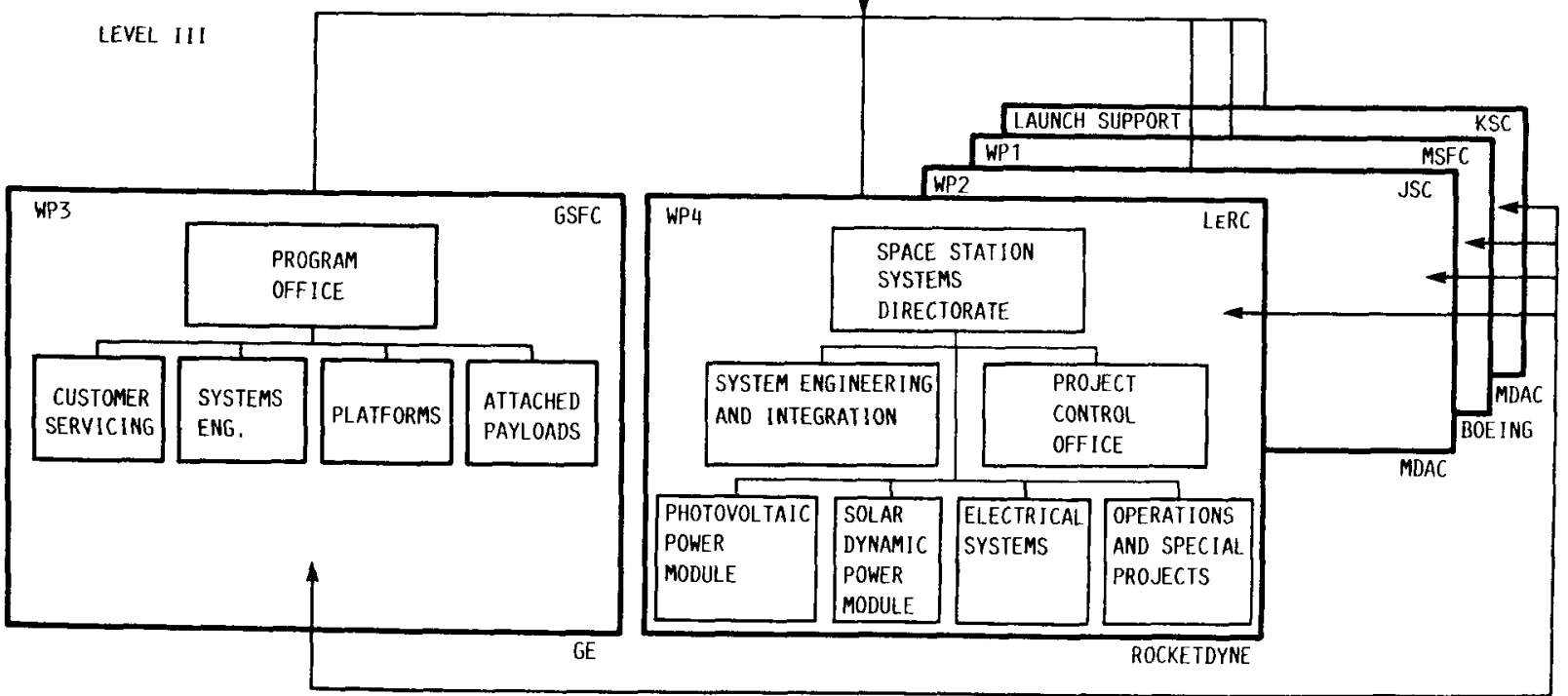

FIGURE 1. - SPACE STATION ROLES. 

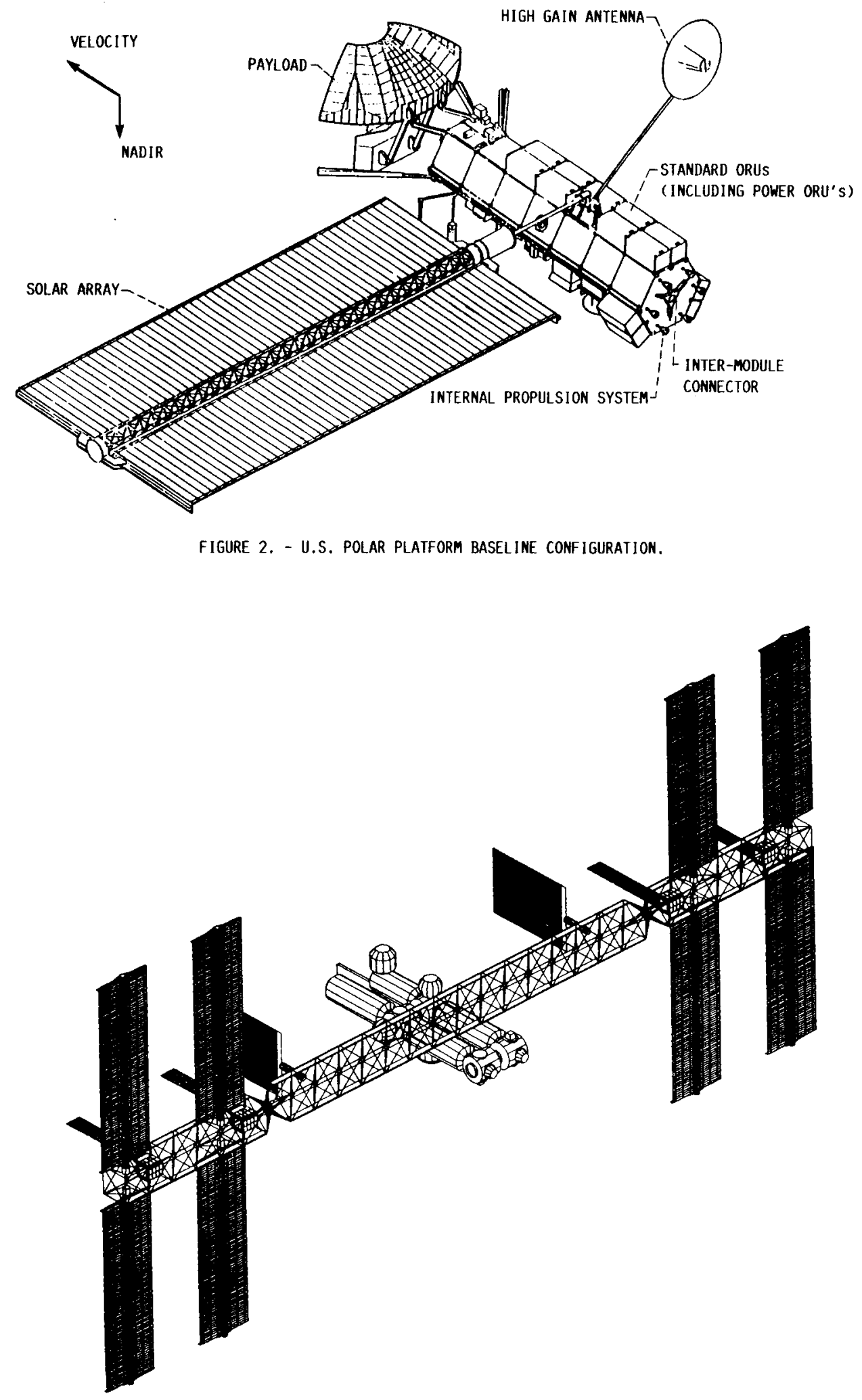

FIGURE 3. - SPACE STATION PHASE 1 BASEL INE CONFIGURATION. 


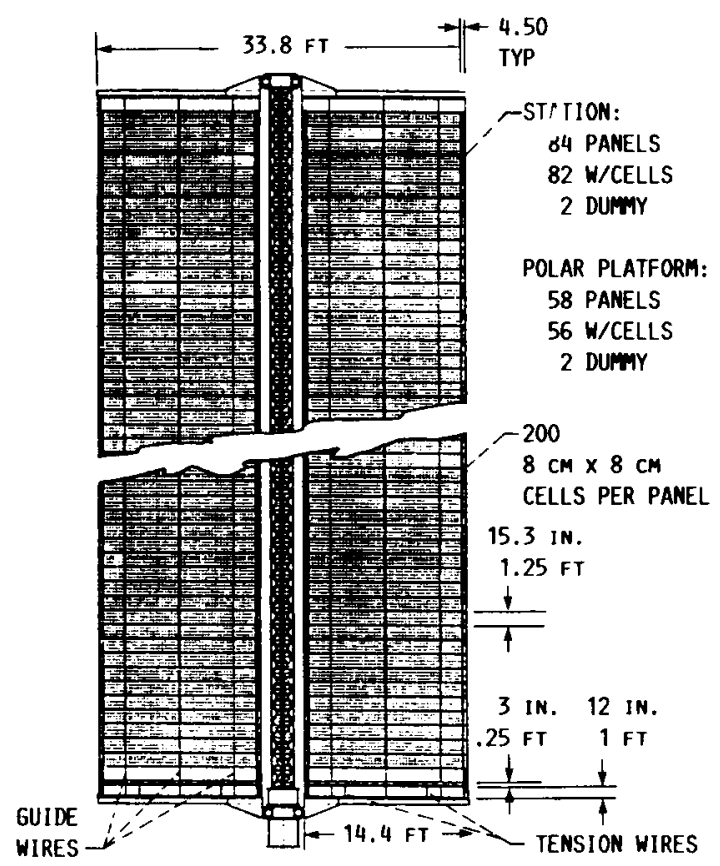

RECONYNDED FOR IOC

\begin{tabular}{|c|c|c|c|c|c|}
\hline \multirow{2}{*}{$\begin{array}{c}\text { ENERGY } \\
\text { STORAGE } \\
\text { TYPE }\end{array}$} & \multirow[t]{2}{*}{ ATTRIBUTE } & \multicolumn{2}{|c|}{ STATION } & \multicolumn{2}{|c|}{ PLATFORM } \\
\hline & & $10 C$ & FUTURE & $10 C$ & FUTURE \\
\hline \multirow{3}{*}{ NiCd } & WE IGHT & LAST & LAST & LAST & LAST \\
\hline & $\operatorname{COST}$ & LAST & LAST & SECOND & LAST \\
\hline & RISK & FIRST & LAST & FIRST & LAST \\
\hline \multirow{3}{*}{$\mathrm{NiH}_{2}$} & MEIGHT & FIRST & FIRST & FIRST & FIRST \\
\hline & $\cos T$ & FIRST & FIRST & FIRST & FIRST \\
\hline & RISK & SECOND & SECOND & SECOND & SECOND \\
\hline \multirow{3}{*}{ RFC } & WE IGHT & SECOND & SECOND & SECOND & SECOND \\
\hline & COST & SECOND & SECOND & LAST & SECOND \\
\hline & RISK & LAST & FIRST & LAST & FIRST \\
\hline
\end{tabular}

FIGURE 5. - EMERGY STORAGE TRADE STUDY RATINGS.

FIGURE 4. - NOVEMBER 1987 BASEL INE STATION AND PLATFORM SOLAR ARRAY DESIGN.

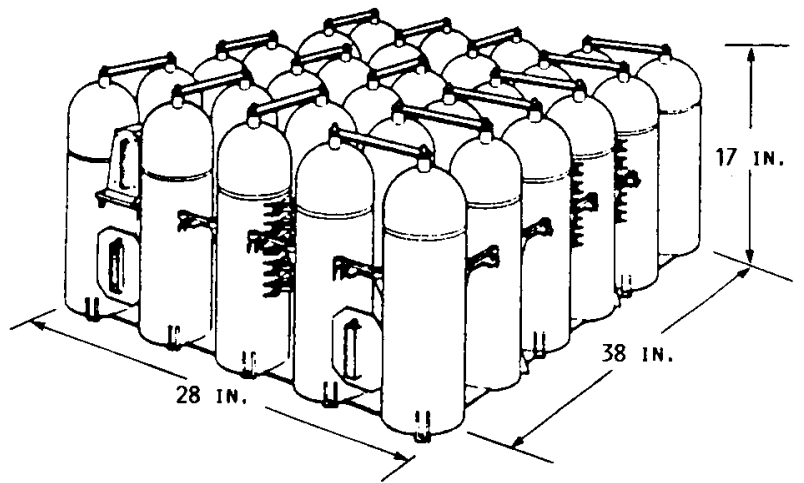

FIGURE 6. - NOVEMBER 1987 BASELINE STATION AND PLATFORM BATTERY ASSEMBLY. 


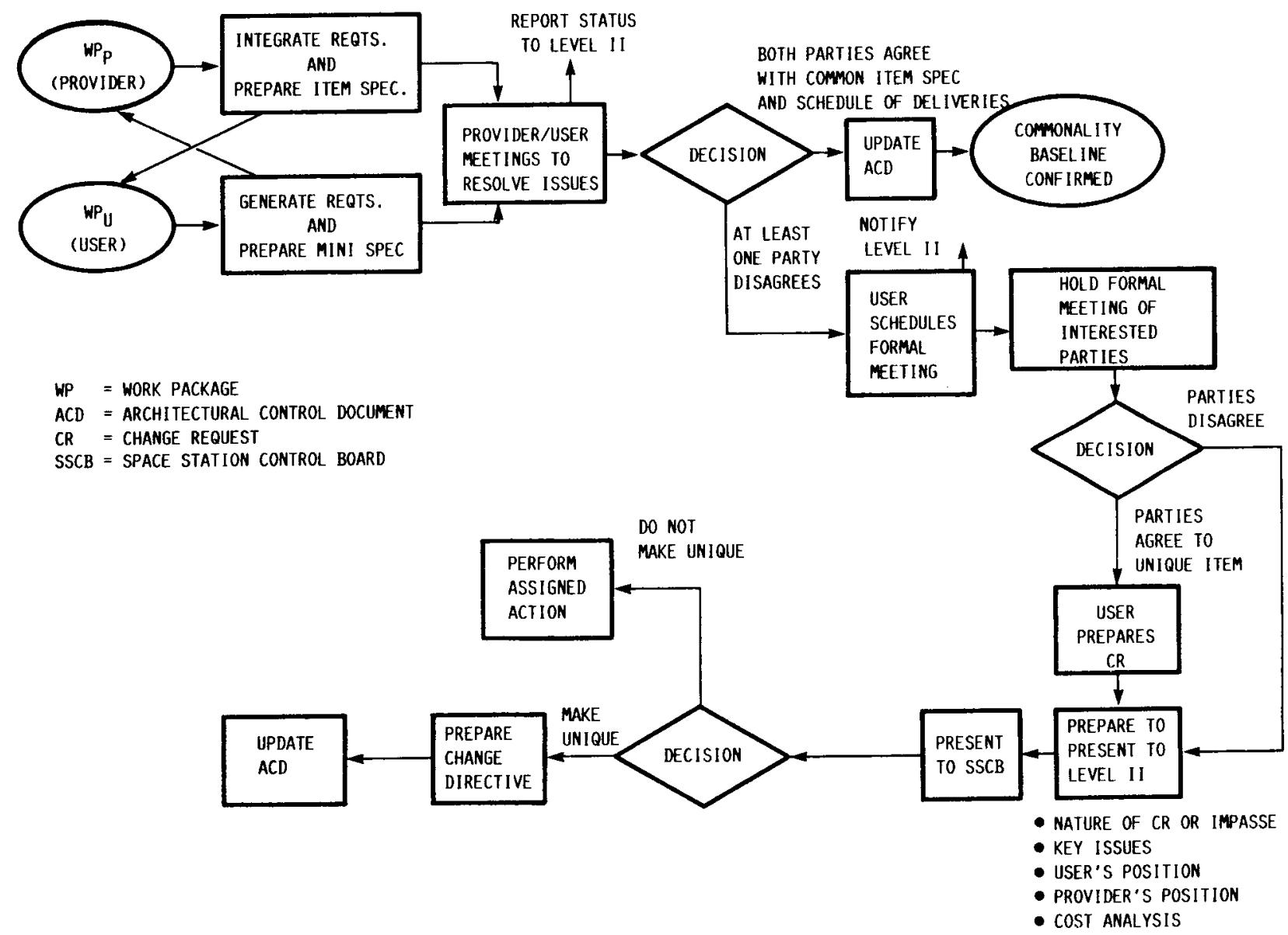

FIGURE 7. - COMMONALITY PROCESS. 


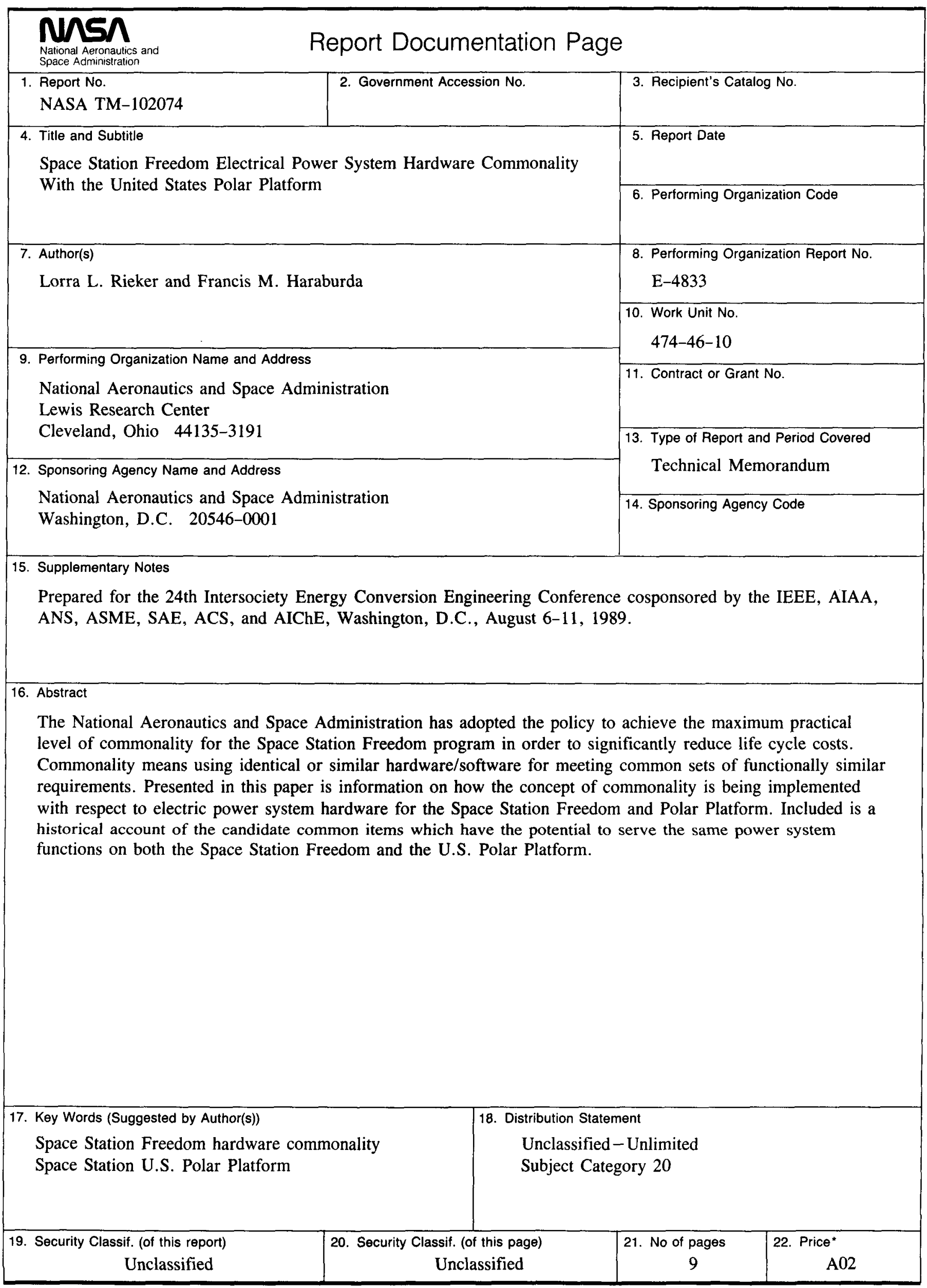

